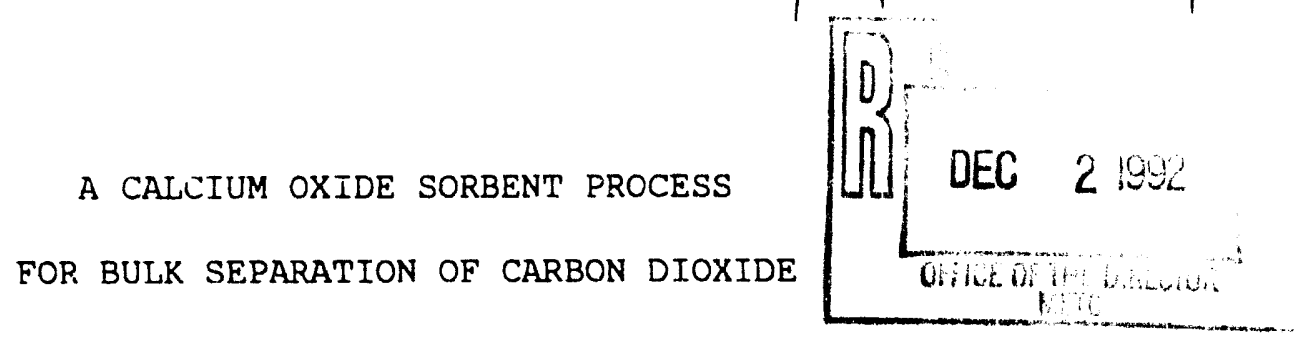

$\mathrm{DOE} / \mathrm{MC} / 26366--3234$

DE93 007550

Contract No. DE-AC21-89MC26366

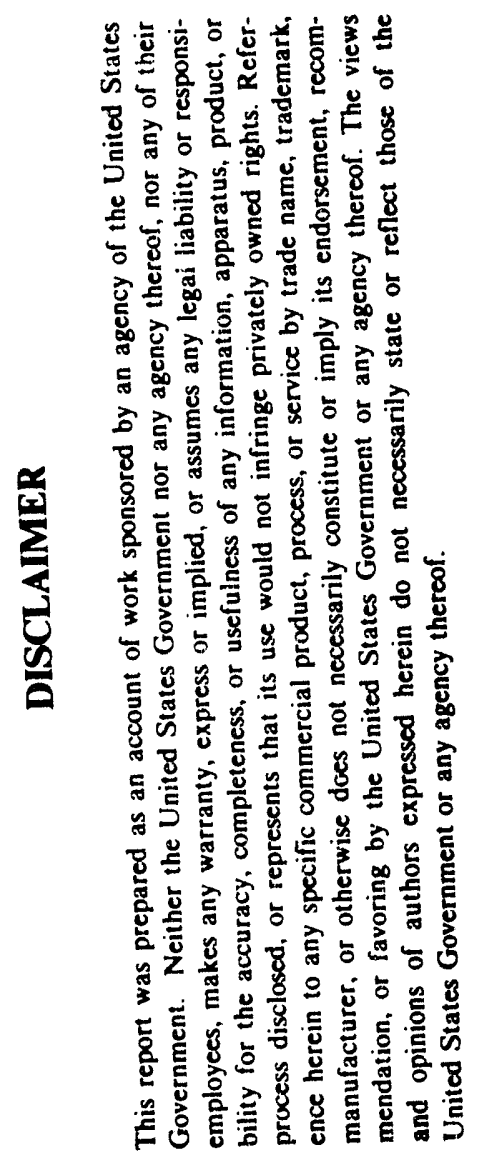

\author{
Quarterly Progress Report 12 \\ July 1992 - September 1992. \\ Department of Chemical Engineering \\ Louisiana State University \\ Baton Rouge, Louisiana 70803 \\ (504) 388-1426
}

Douglas P. Harrison

Principal Investigator

October 1992 
EXECUTIVE SUMMARY

This research project is investigating the technical feasibility of a high-temperature, high-pressure (HTHP) process for the bulk separation of $\mathrm{CO}_{2}$ from coal-derived gas. The original contract for two years was awarded in september 1989 as a result of solicitation number DE-RA21-89MC26040 entitled "Novel Concepts for Bulk Separation of Gases in Coal Gasification Systems." Two no-cost extensions without a change in the statement of work extended the performance period by six months to March 1992. At that time a two-year contract extension with an enlarged scope of work and additional funding was approved so that the research is now scheduled to end in March 1994.

Phase I research, in which an electrobalance reactor was used to establish the technical feasibility of the regenerable sorbent process, was completed in March 1992 and results have been fully described in earlier quarterly reports. In Phase $I$, the calcination and carbonation characteristics of three calcium sorbents were studied as a function of calcination and carbonation temperature and pressure, mol fraction $\mathrm{CO}_{2}$ in the carbonation gas, and carbonation background gas composition. Desirable reaction conditions required for high reactivity and good sorbent durability were determined. Multicycle tests consisting of as many as ten complete calcination and carbonation cycles were completed. Indirect evidence which suggested that the water-gas shift reaction occurred simultaneously with $\mathrm{CO}_{2}$ removal was found. Occurrence of the simultaneous reactions created the possibility of a direct one-step process for the manufacture of hydrogen from soal-gas while at the same time separating $a$ concentrated stream of $\mathrm{CO}_{2}$. The concentrated $\mathrm{CO}_{2}$ stream could be quite significant if, in the future, environmental regulations restrict atmospheric $\mathrm{CO}_{2}$ emissions. 
Phase II research involves a scale-up from microgram to gram quantities of sorbent and a switch from the electrobalance reactor to a fixed-bed reactor with capability for feed and product gas analysis. In the previous quarterly report the initial design concepts for the fixed-bed reactor system and gas chromatograph specifications were described. The chromatgraph has been received and initial gas calibration tests were completed during the current quarter. In addition, minor design refinements during construction of the fixed-bed reactor have been made. As of the beginning of october all major components of the fixed-bed reactor system have been received and system assembly is ready to begin.

\section{FIXED-BED REACTOR}

Figures 1 and 2 are diagrams of the reactor system and the fixed-bed reactor, respectively. Only minor modifications to the diagrams presented in the previous report have been made.

The two manual valves used to control whether feed or product gas is directed to the chromatograph sampling system have been replaced by a single manually operated four-way sampling valve. In addition, the two needle valves included in the product and by-pass feed lines have been omitted. We plan for the entire stream flow to pass through the four-way sampling valve. Gas flows during sampling and analysis will be described in the following section. The only change made in the fixed-bed reactor involved replacing the split tubing which supports the bottom porous stainless steel disk with a non-split tubing support. We believe that this change will make loading and unloading the reactor easier. All other parts of the reactor system and the fixed-bed reactor remain as described in the previous quarterly report. 


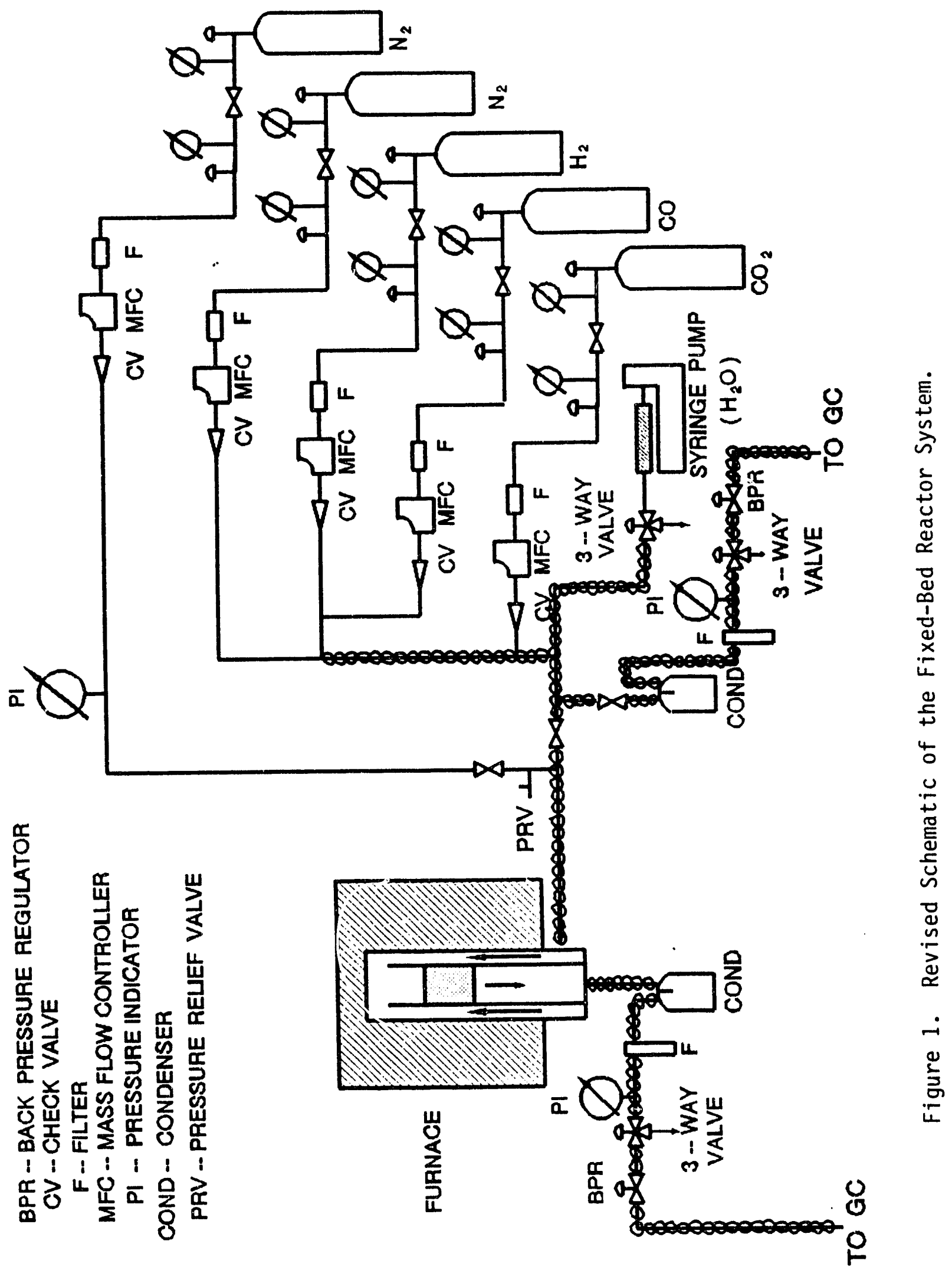




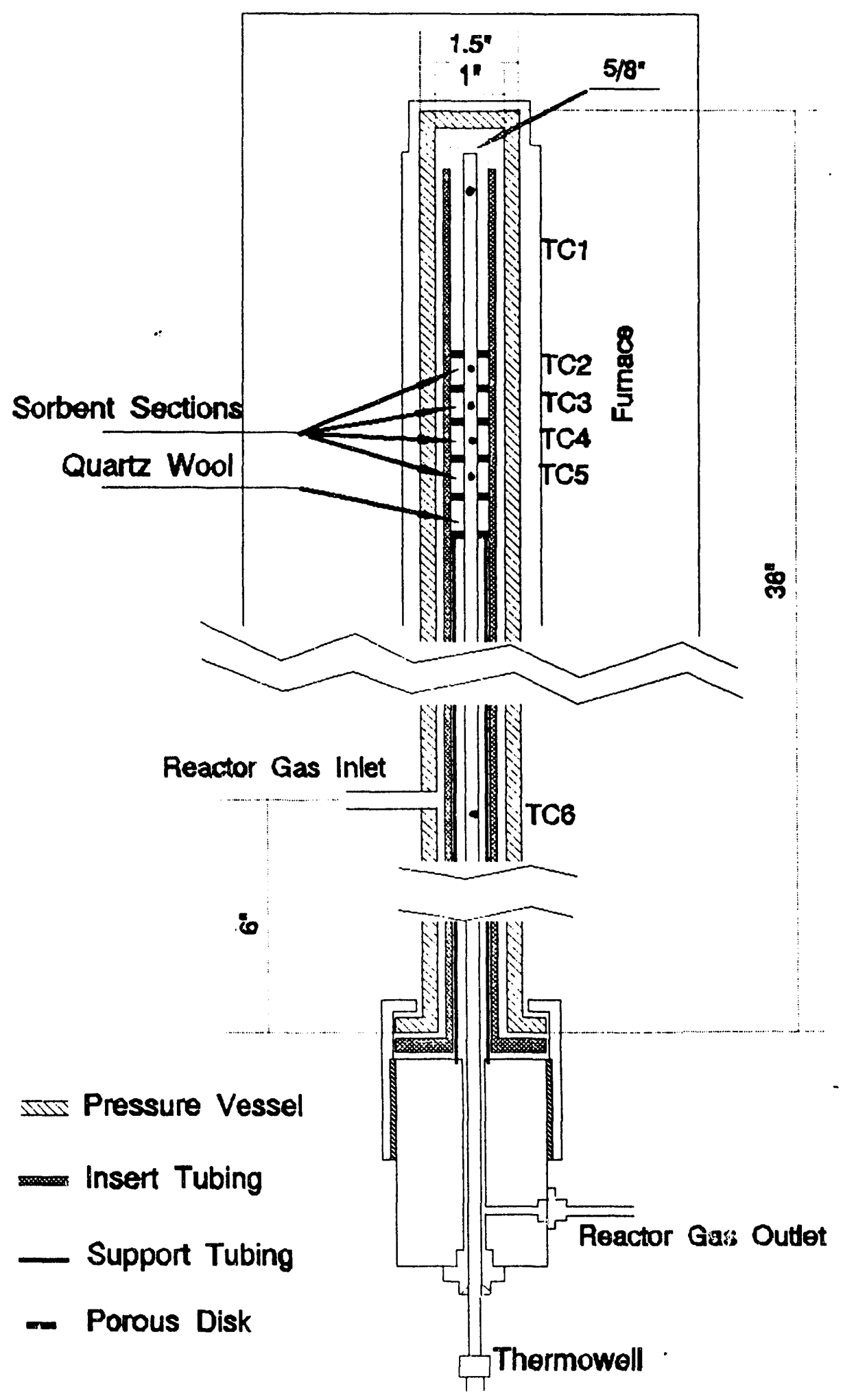

Figure 2. Revised Diagram of the Fixed-Bed Reactor. 
The thermowell containing the six axially spaced thermocouples (see Figure 2) proved to be the rate limiting step in reactor construction. Special fabrication was required and the thermowell had to be returned twice to the fabricator vive to problems with the connecting wires. A proper system was received in late september so that system assembly and testing should occur in October.

\section{GAS ANALYSIS}

The Shimadzu GC-14A gas chromatograph was delivered in late August and installation and operator training were completed in september. Installation and training were delayed by Hurricane Andrew. The GC is equipped with a thermal conductivity detector (TCD), a nickel-catalyzed methanizer, and a flame ionization detector (FID). Nitrogen will be used as the carrier gas and hydrogen will be analyzed using the TCD. We had originally hoped to be able to analyze high concentrations of $c 0$ and $\mathrm{CO}_{2}$ on the TCD as well, but initial calibration tests indicate that this will not be possible. The thermal conductivities of $\mathrm{CO}$ and $\mathrm{CO}_{2}$ are too close to the thermal conductivity of the $\mathrm{N}_{2}$ carrier gas. Instead, $\mathrm{CO}$ and $\mathrm{CO}_{2}$ will be converted to $\mathrm{CH}_{4}$ in the methanizer and then analyzed wing the FID. The FID is irsensitive to $\mathrm{H}_{2}$ since a hydrogen flame is used in the burner.

Initial testing of the chromatograph was carried out using a calibration gas of the following composition.

$\begin{array}{ll}\mathrm{H}_{2} & 18.05 \% \text { (vol) } \\ \mathrm{CO} & 12.21 \% \\ \mathrm{CO}_{2} & 9.93 \% \\ \mathrm{~N}_{2} & \text { balance }\end{array}$


A typical chromatogram is shown in Figure 3. Chromatograph conditions were as follows.

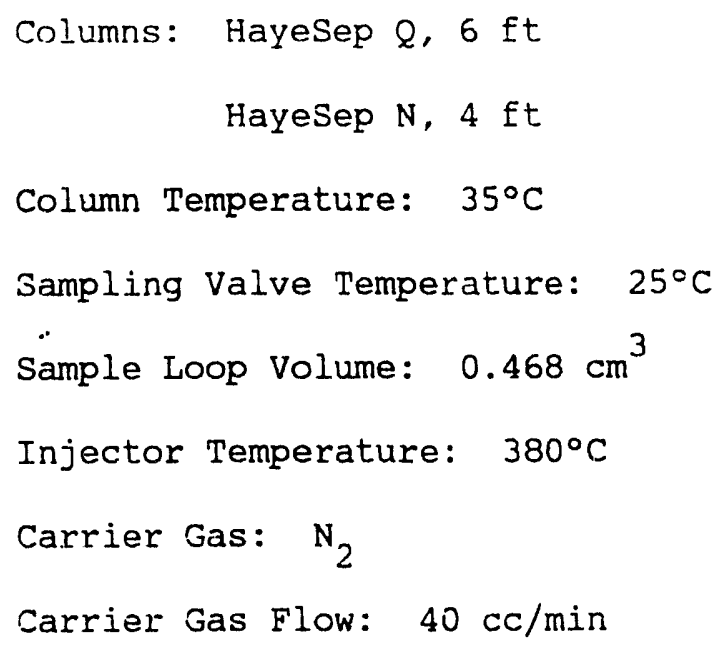

$\mathrm{H}_{2}$ with a retenticr time of 0.558 minutes and a peak area of $1,189,327$ is shown in the channel B (TCD) report. The minor peak at about 2.3 minutes is $\mathrm{CO}_{2}$ while $\mathrm{CO}$ is not detected with the TCD. CO with a retention time of 1.325 minutes and $\mathrm{CO}_{2}$ with a retention time of 2.88 ininutes are detected on channel $A$ (FID). The peak areas for $\mathrm{CO}$ and $\mathrm{CO}_{2}$ are $3,664,873$ and $2,454,254$, respectively.

The peak areas obtained from 20 separate injections of the calibration gas are shown in Figure 4. The means and the percent standard deviations for each component are also shown on the figure. Hydrogen reproducibility is quite good with the per cent standard deviation only $\pm 1 \%$ of the mean. There is greater deviation in the CO and $\mathrm{CO}_{2}$ analyses with percent standard deviations of $2.9 \%$ and $5.6 \%$, respectively. It is important to note that the $\mathrm{CO}$ and $\mathrm{CO}_{2}$ trends from sample to sample are similar. This is, high area counts for co are matched by high area counts for $\mathrm{CO}_{2}$, and vice versa. We believe that these deviations are the result of injection pressure differences from sample to sample. The deviation should be reduced when a continuous flow injection system is used in further calibration tests. 
Channel A Report

\begin{tabular}{llrrrrr} 
Name & Time & \multicolumn{1}{l}{ Area } & Axea & Helght & Helght & Conc (mol \\
\hdashline Co & -1.325 & 3664873 & 59.892 & 166851 & 66.222 & 12.21 \\
Co2 & 2.883 & 2454254 & 40.108 & 85106 & 33.778 & 9.93 \\
Continued... & & & &
\end{tabular}

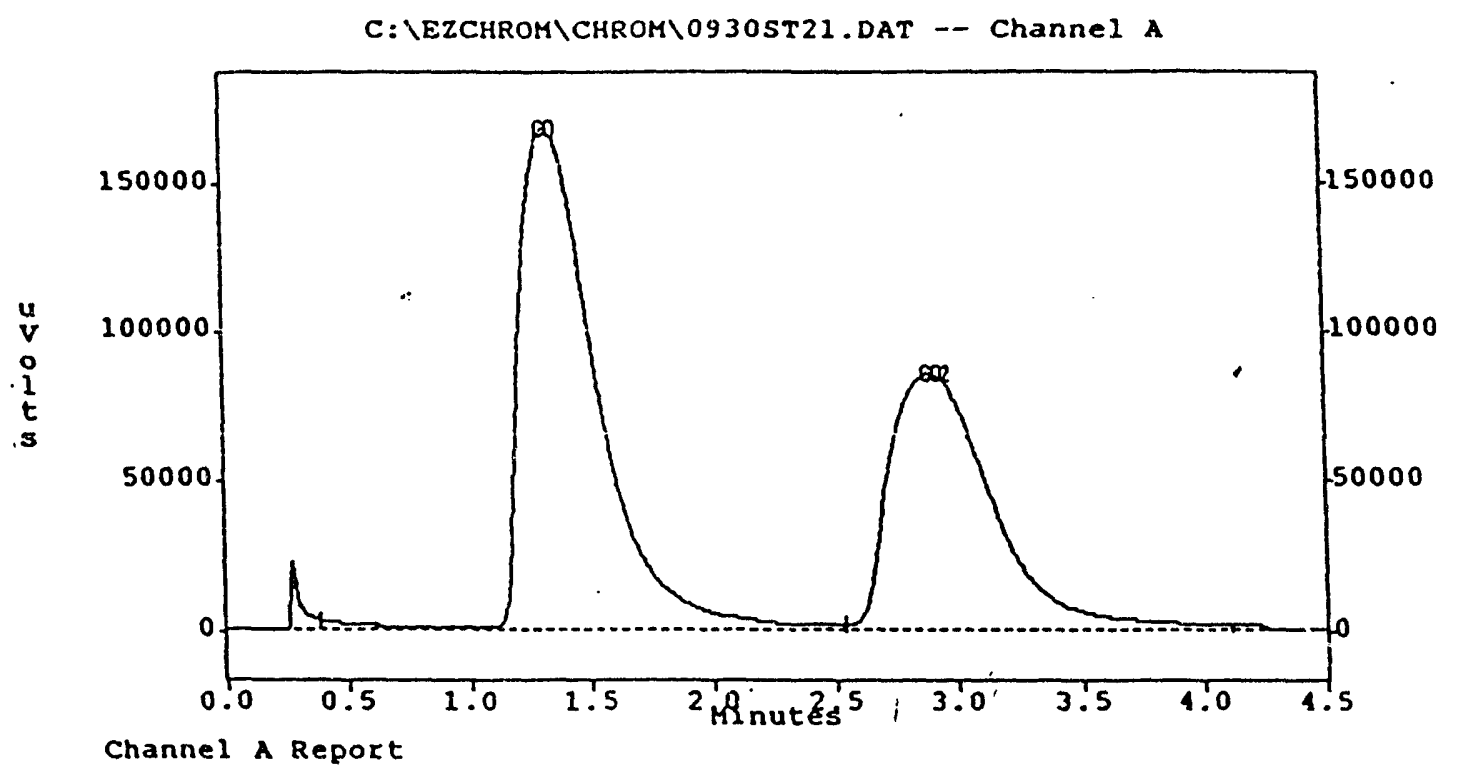

Channel B Report

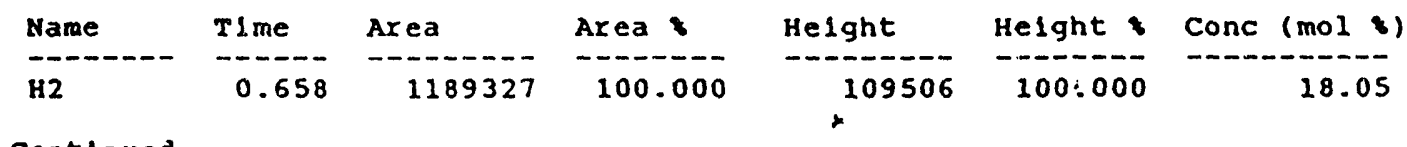

Continued...

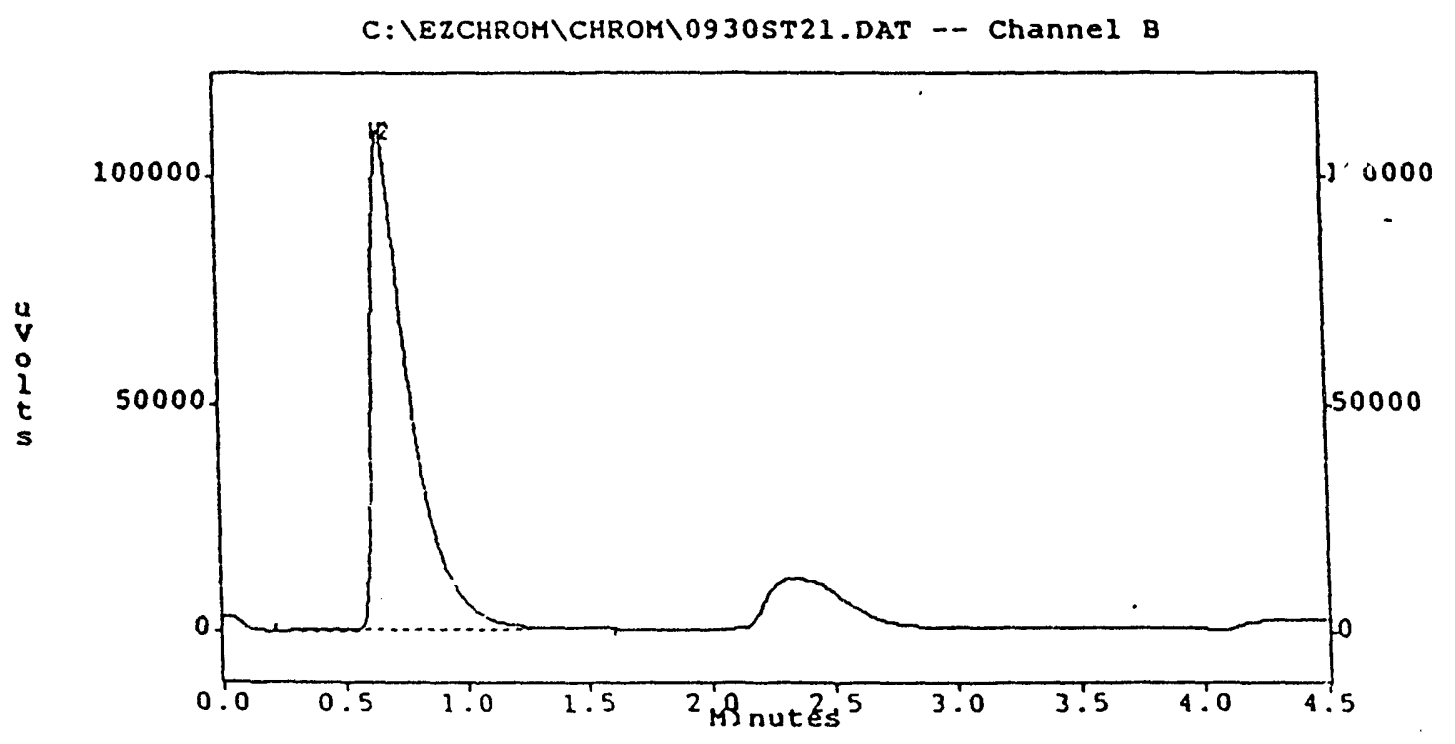

Channel B Report

Figure 3. Chromatogram of Gas Calibration Mixture. 


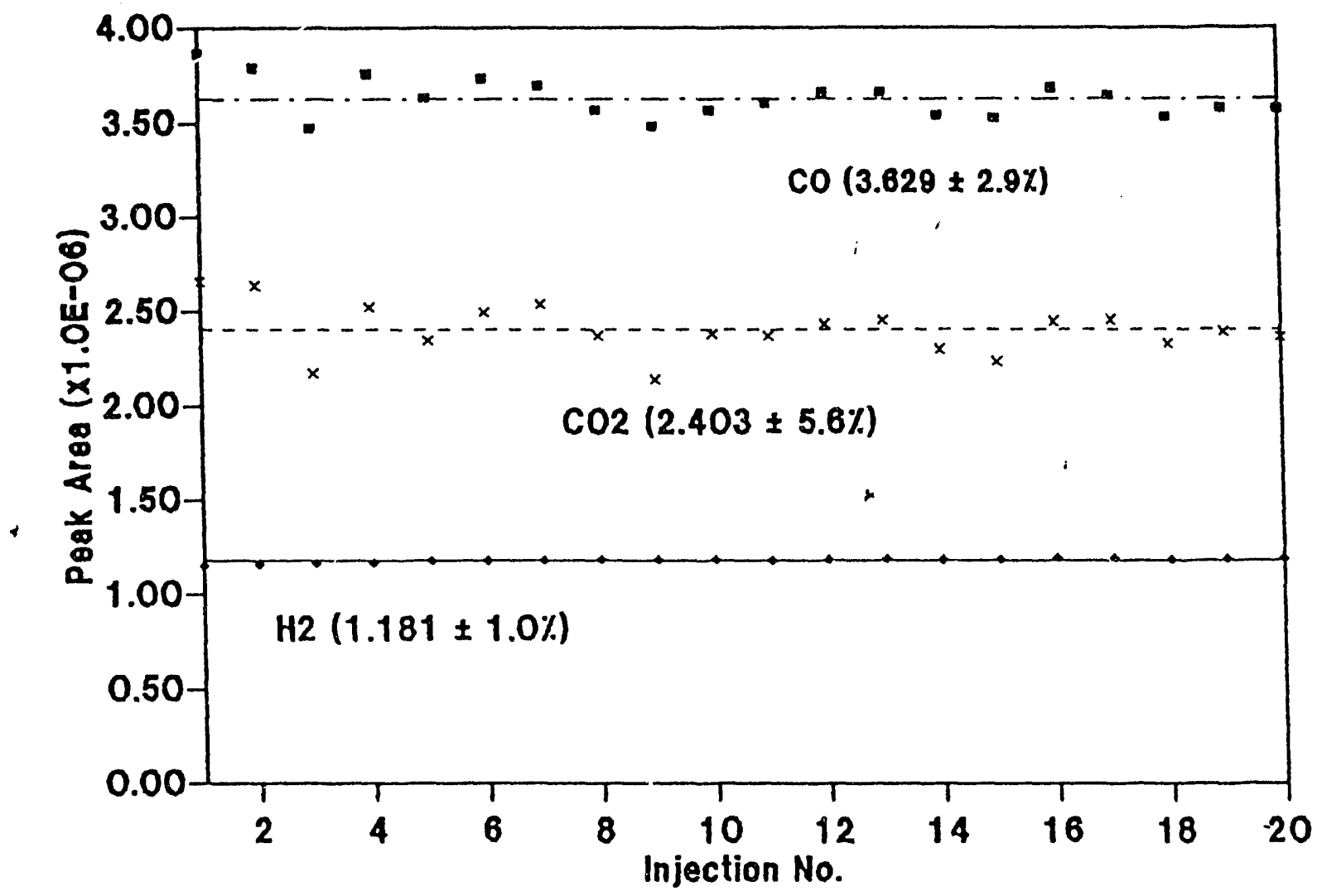

Figure 4. Chromatograph Area Counts for Multiple Injections of Calibration Gas. 
Figure 5 compares the individual response factors from the 20 arialyses of the calibration gas. As before, the response factor for Co is taken to be 1.0. The mean and per cent standard deviation values of the response factors for $\mathrm{CO}_{2}$ and $\mathrm{H}_{2}$ are shown on the figure. The relative deviation in $\mathrm{f}_{\mathrm{CO}_{2}}$ is smaller than for $\mathrm{f}_{\mathrm{H}_{2}}$ since the response factor depends on the ratio of component peak areas. As previously shown in Figure 4, the peak area for $\mathrm{H}_{2}$ is relatively constant, and, while there is greater variation in the peak areas for $\mathrm{CO}$ and $\mathrm{CO}_{2}$, the peak area ratios remains approximately constant.

The choice of chromatograph operating conditions always represents a compromise between opposing factors. For this study we wish to minimize elution time (to allow more frequent sampling) while maintaining appropriate component peak resolution. The arrangement of sampling valves and columns in the GC system is shown in Figure 6 . Three sampling valves, V1, V2, and V3, are included. The four-port valve (V1) determines whether the reactor product or by-passed reactor feed is sampled. The ten-port and six-port valves are automatically actuated and control component separation. The GC is also equipped with three columns. HayeSep N (HSN) serves as a water trap and captures water vapur which escapes from the condenser. As shown in Figure 6, the water vapor captured on HSN during the step 2 sampling operation is back flushed from the column and vented in step 3.

Separation of $\mathrm{H}_{2}, \mathrm{CO}$, and $\mathrm{CO}_{2}$ occurs on the Hayesep \& (HSQ) column with the valves in the step four position. The design arrangement assumed that satisfactory resolution of $\mathrm{H}_{2}$ and $\mathrm{CO}$ could not be accomplished in HSQ, and the molecular sieve (MS) column would be 


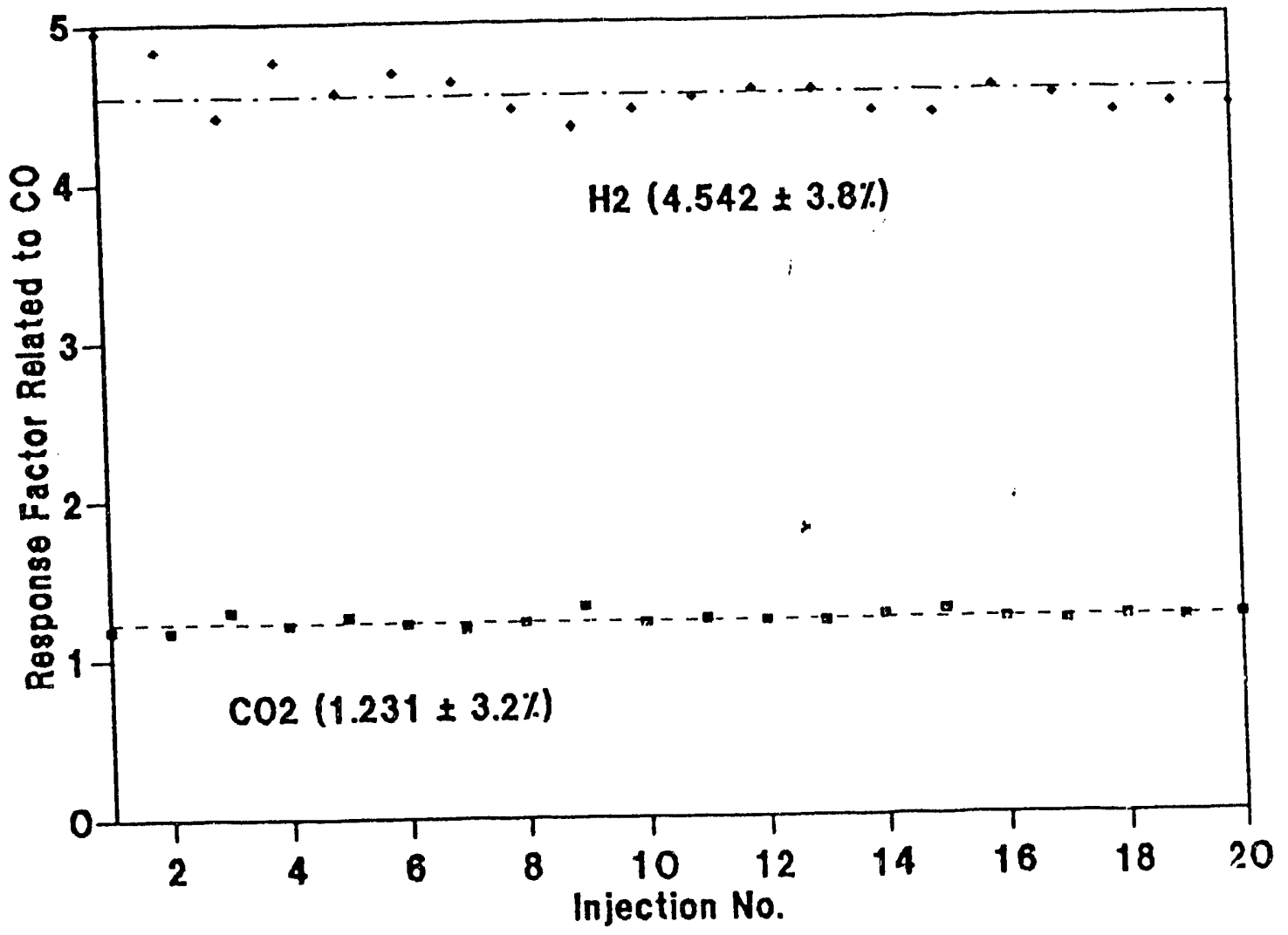

Figure 5. Chromatograph Response Factors From Multiple Injections of Calibration Gas. 


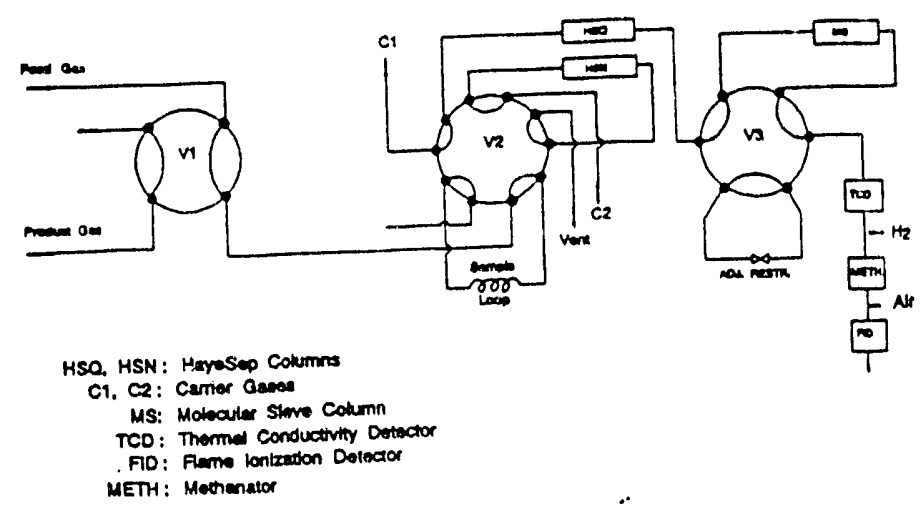

GC OPERATION - STEP ONE

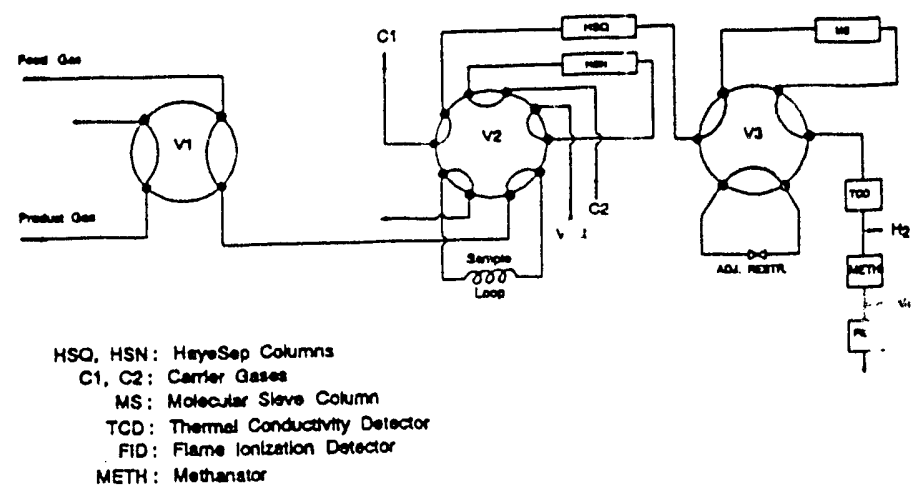

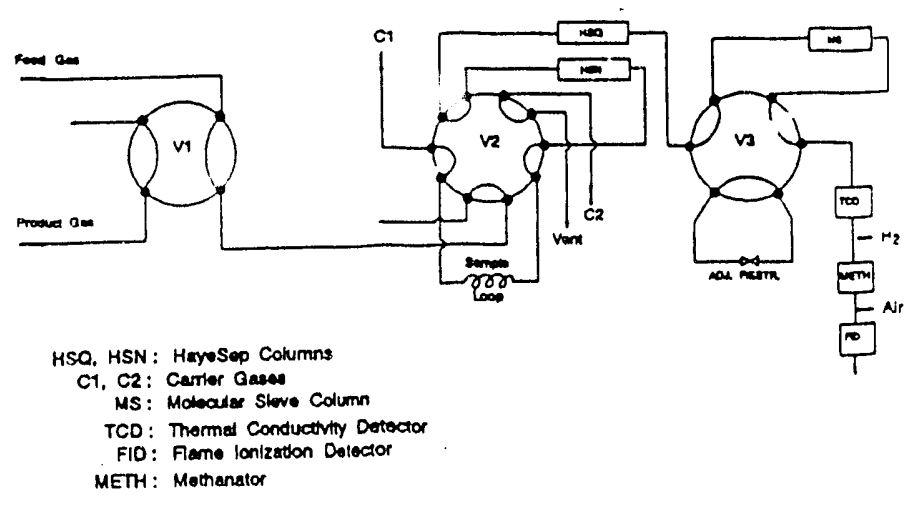

GC OPERATION -... STEP TWO

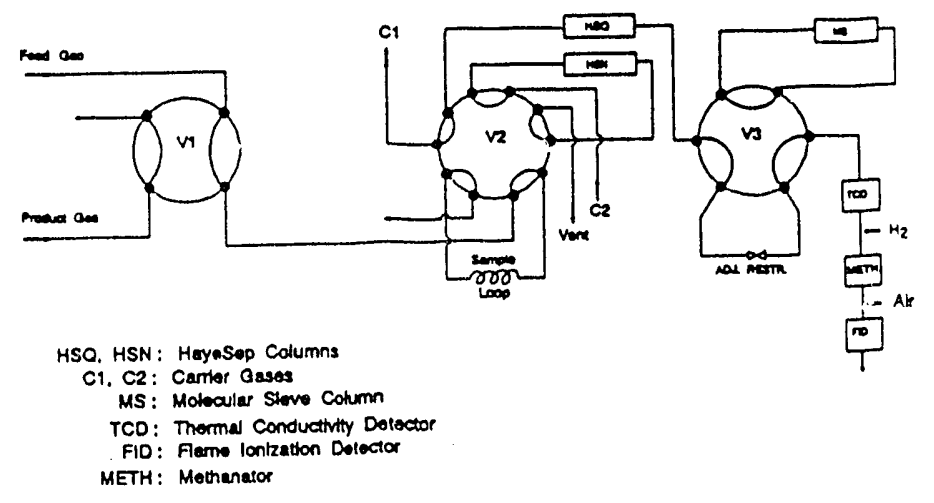

GC OPERATION - STEP FOUR

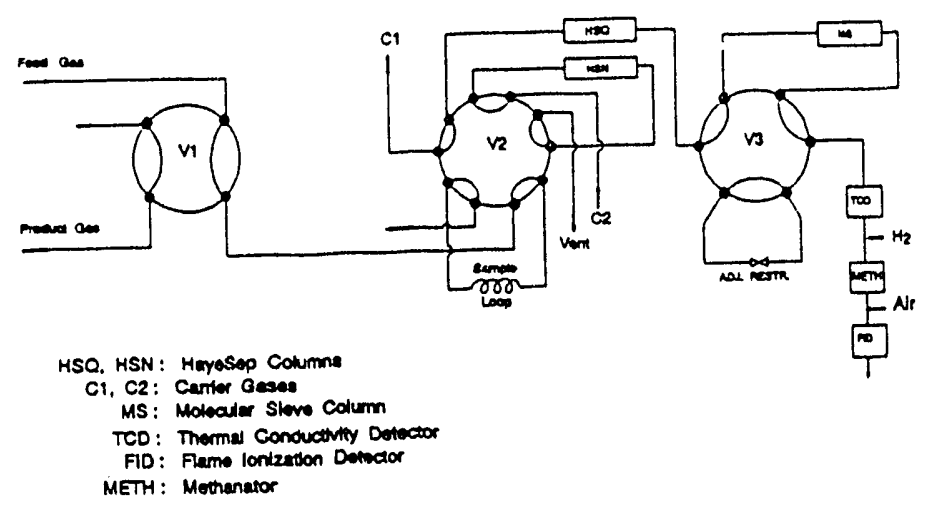

GC OPERATION - STEP FIVE

Figure 6. Five-Step Sampling Valve Sequence With $\mathrm{H}_{2}$ and $\mathrm{CO}$ Separation on the Molecular Sieve Column. 
required. However the chromatogram shown ir. Figure 3 was obtained using only HSQ; the MS column was not required. If, indeed, it turns out that satisfactory resolution of the Laree comfonents at all concentration levels of interest can be obtained using only HSQ, the simpler three-step sampling valve sequence shown in Figure 7 can be used. In this sequence, the MS column is always isolated from the analysis loop and $v 3$ remai.zs in the indicated position. 


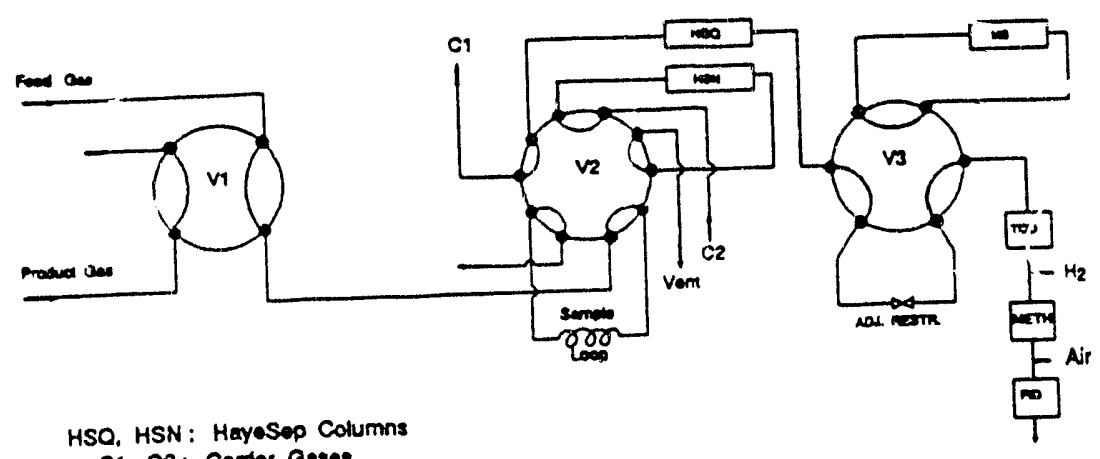

C1, C2: Camter Gasto

MS: Molecaler Sleve Column

TCD: Thermal Conductivity Detector

FIO:- Fame lonization Detector

METH : Mothanator

GC OPERATION - STEP ONE

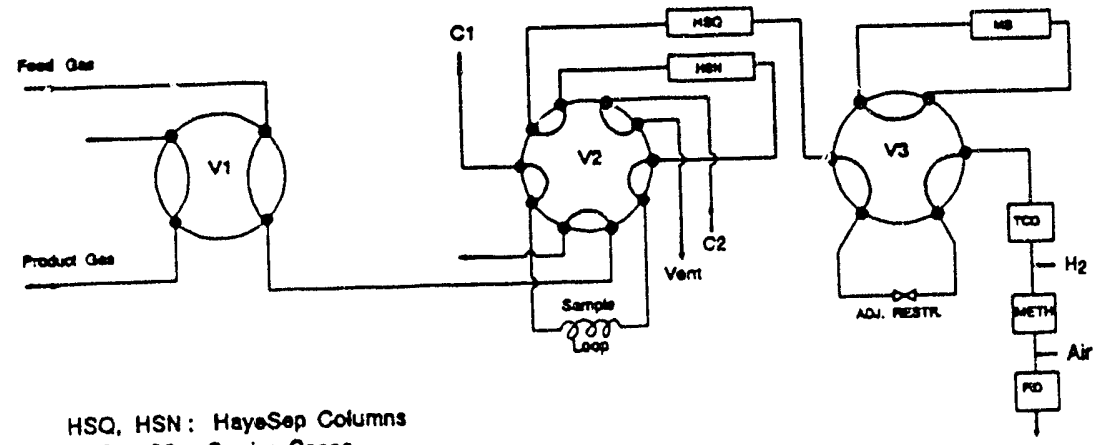

C1, C2: Carrier Gases

MS: Molec ins Sievo Column

TCD: Thermal Conductuty Detector

FID: Fame lonization Detector

METH : Mothanato

GC OPEPATION - STEP TWO

ron ans
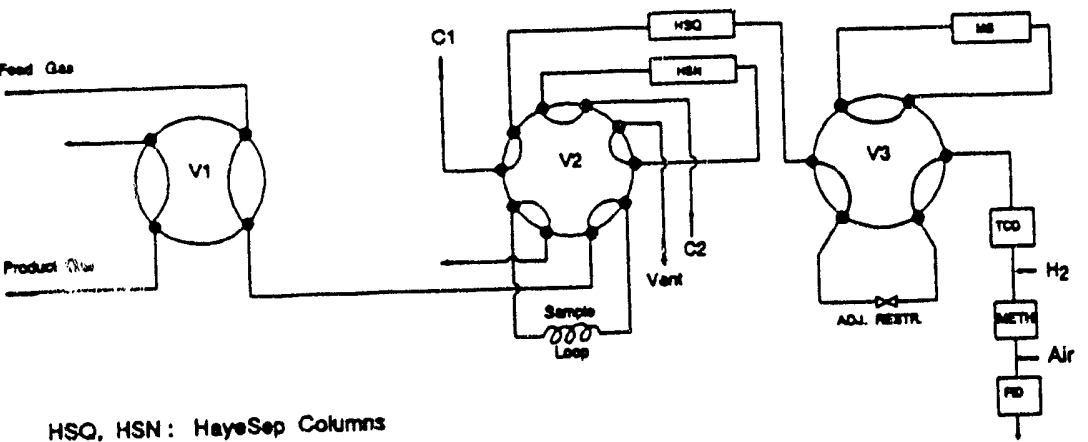

HSO, HSN : HayeSep Columns

C1, C2: Carter Gases

MS: Molecule Slove Cotumn

TCD: Therme Conductivin Dotector

FID: Flame Ionization Detector

METH : Mothanator

GC OPERATION - STEP THREE

Figure 7. Three-Step Sampling Valve Sequence With $\mathrm{H}_{2}, \mathrm{CO}$, and $\mathrm{CO}_{2}$ Separation on the HayeSep Q Column. 
U.S. Neportment of Eneryy

Morgar: wn Enelgy Technology Center

Attn: Contractor Reports Receipt Coordinator, M/S F07

Box 880, 3610 Collins Ferry Rd.

Morgantown, WV $2650 \%$

To Whom It May Concern:

Re: Concract DE-AC21-89MC26366

Enclosed please find two copies of Quarterly Progress Report 12 for the above referenced contract. This report covers activities between July 1, 1992 and September 30, 1992.

Please contact me if you need additional information.

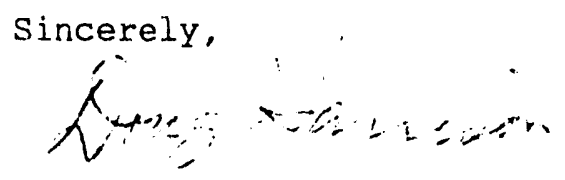

Douglas P. Harrison

Alumni Professor

$\mathrm{DPH} / \mathrm{dd} / 21$

rc: Dr. Venkat $K$. Venkataraman

U.S. Department of Energy

Morgantown Energy Technology Center

Box 880, 3610 Collinis Ferry Road

Morgantown, WV 26507 
$\because$
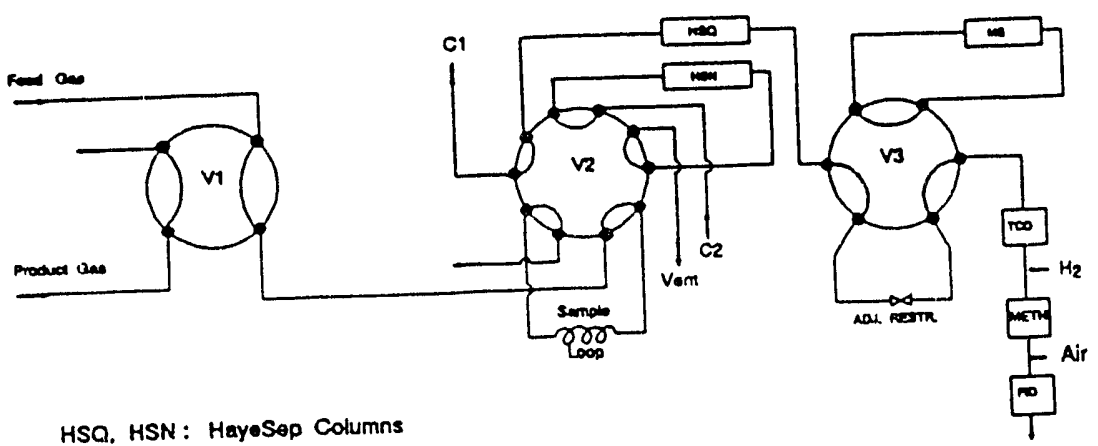

HSO HSN : HayoSop Columns

C1, C2: Camter Gases

MS: Motecular Sleve Column

TCD: Thermal Conductivity Detector

FID: Flame Ionization Delector

METH : Mothanator

GC OPERATION - STEP ONE

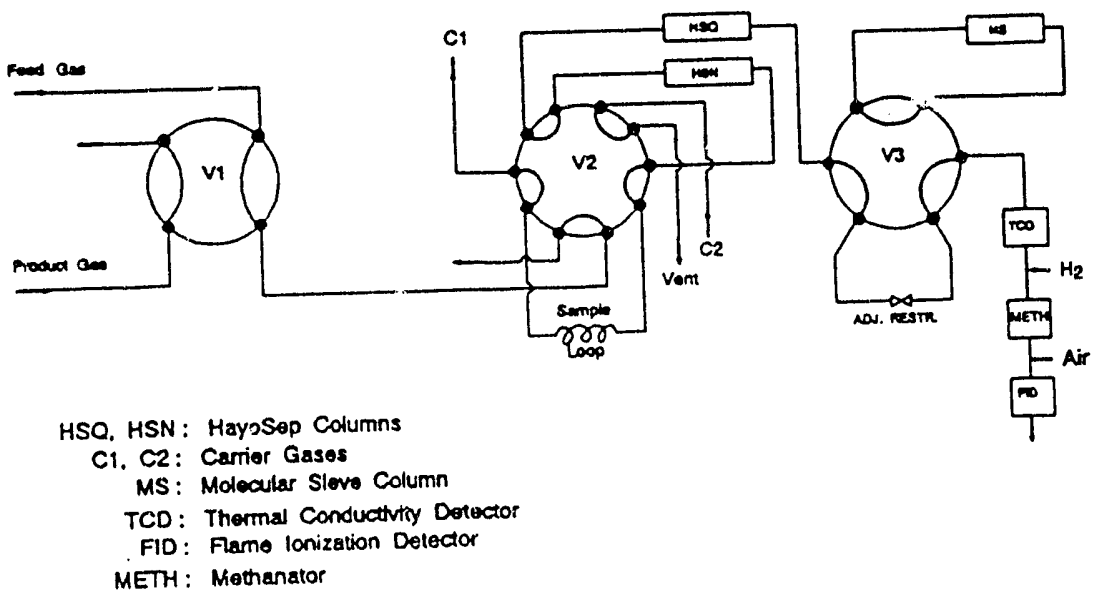

GC OPERATION - STEP TWO
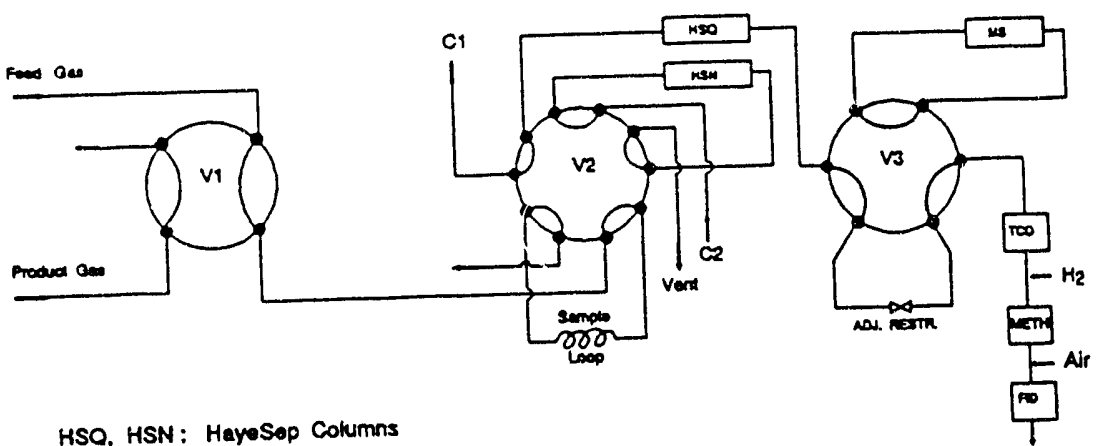

HSO, HSN : HayoSop Columns

C1, C2: Carter Gases

MS: Molecular Sieve Coturnn

TCD: Thermel Conductutty Delector

FID: Flame lonization Detector

METH : Mothanator

GC OPERATION - STEP THREE

Figure 7. Three-Step Sampling Valve Sequence With $\mathrm{H}_{2}, \mathrm{CO}$, and $\mathrm{CO}_{2}$ Separation on the HayeSep Q Column. 

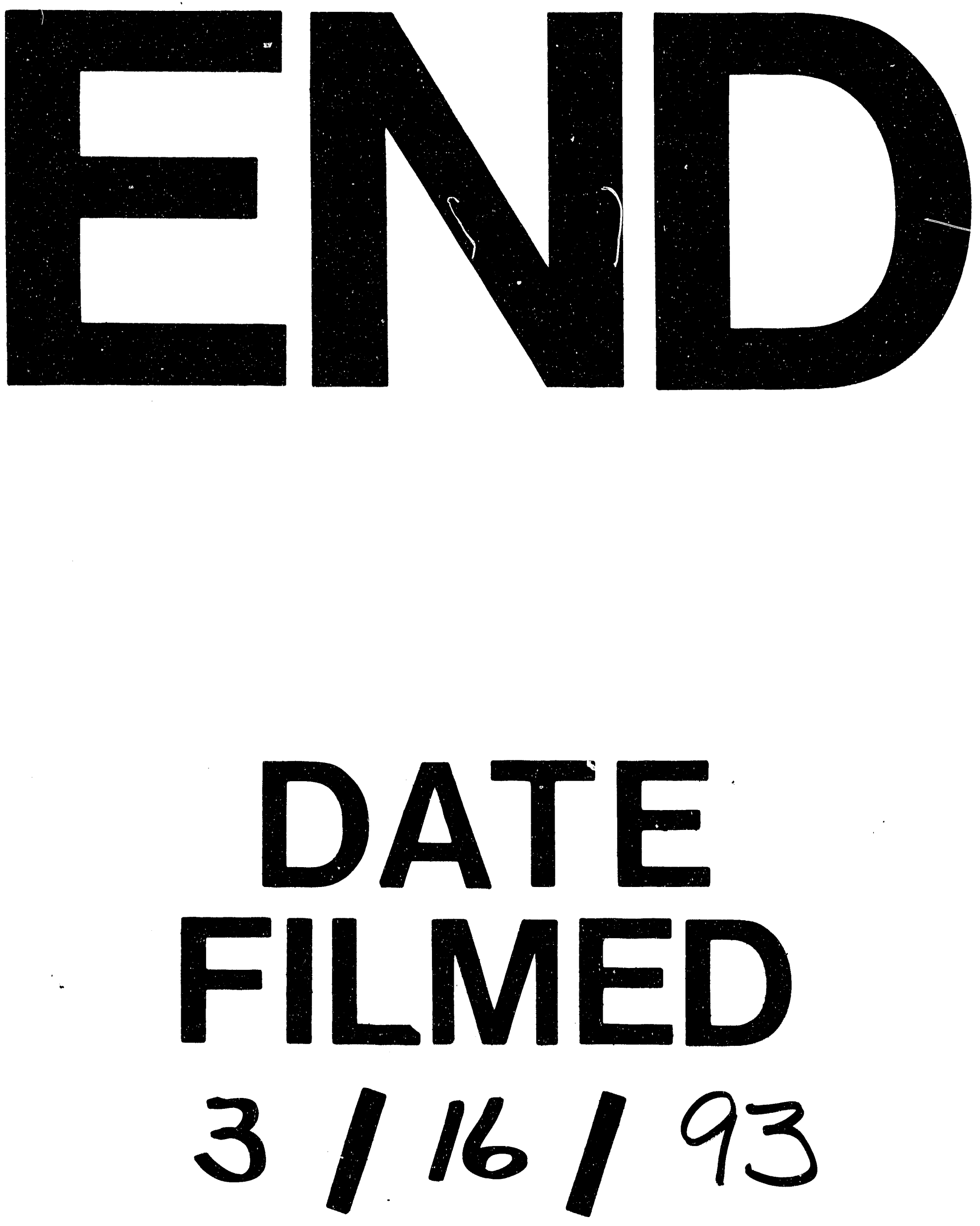
-

$=$

$\equiv$ 